\title{
Experimental Study on Impact Load Resistance of RC Beam with Corroded Reinforcement
}

\author{
Isao Kuwahara ${ }^{1, a}$, Hiroki Tamai ${ }^{1}$ and Yoshimi Sonoda ${ }^{1}$ \\ ${ }^{1}$ Department of Civil Engineering, Kyushu University, 744 Motooka Nishi-ku, Fukuoka 819-0395, Japan
}

\begin{abstract}
In Japan, many concrete bridges along the coastline have suffered corrosion due to the chloride attack from seawater and airborne salt. Therefore, now, several researches on corroded RC structures have been ongoing around the world. Especially, as a basic research, many researchers have studied on the numerical and experimental method to evaluate static load resistant capacity of RC beams with corroded reinforcements. However, there has been almost no research to evaluate impact load resistant capacity. Of course, it is important that impact load resistant capacity is clarified, if the possibility of acting of impact load including in natural disaster on corroded RC structures is dealt with. With a background like this, this paper describes an experimental investigation of the structural behavior of corroded RC beams. To be precise, in this study, RC beams with corroded reinforcement by using electrolytic corrosion method were made, and both of static loading test and repeated impact test for those $\mathrm{RC}$ beams were conducted in order to clarify the static and impact load resistant capacity of them. As a result, we could get some findings. At first, through repeated impact tests (which has $1.0 \mathrm{~m} / \mathrm{s}$ impact velocity and a $100 \mathrm{~kg}$ steel weight), the number of impacts to the failure of corroded RC beams were less than half of healthy RC beams. It was also found that fracture pattern was completely different due to some axial cracks by corrosion. In addition, even though the corrosion rate is same level, the impact load resistant capacity reduce greatly compared to the static load resistant capacity because of the existence and pattern of cracks due to corrosion.
\end{abstract}

\section{Introduction}

The deterioration of reinforced concrete structures due to chloride-induced corrosion of the steel reinforcement is one of the most considerable problems against many infrastructures in civil engineering field all over the world [1]. Especially, the development of the countermeasure against several deteriorations of the structures is an urgent issue in also Japan. Here, the major effect of the corrosion process is the formation of rust and these results in cracking and falling of the cover concrete, which can influence various characteristics such as the mechanical and structural performance and load capacity of the RC structures. To properly maintain some aged RC structures, it is important to quantitatively evaluate the load capacity of them against several loadings such as static and impact loading. So, several researches on corroded RC structures have been ongoing around the world in recent days. Especially, as a basic research, many researchers have studied on the numerical and experimental method to evaluate static load resistant capacity of RC beams with corroded

\footnotetext{
${ }^{a}$ Corresponding author : kuwahara@doc.kyushu-u.ac.jp
} 
reinforcements [2]. However, there has been almost no research to evaluate impact load resistant capacity. Of course, it is important that impact load resistant capacity is clarified, if the possibility of acting of impact load including in natural disaster on corroded RC structures is dealt with.

In this study, to get fundamental findings regarding impact load resistant capacity of RC beams with corroded reinforcement, the impact loading test was conducted for the damaged RC beams. In addition, the static loading test was conducted to investigate the basic characteristics of the RC beam with corroded reinforcement and to compare the results of the static and impact loading test with corrosion ratio.

\section{RC Beams Damaged by Electrolytic Corrosion Method}

Figure 1 shows an arrangement of reinforcement and dimensions of the specimen. The length of the RC beam specimens was $1200 \mathrm{~mm}$ (span length: $1000 \mathrm{~mm}$ ), and the cross-sectional dimensions were $120 \times 100 \mathrm{~mm}$. The thickness of the cover concrete was $19 \mathrm{~mm}$. The deformed reinforcements $(10$ $\mathrm{mm}$ diameter) were used as the tensile reinforcements in each beam. The round reinforcements $(6 \mathrm{~mm}$ diameter) were used as the compression reinforcements and as stirrup which were placed with 100 $\mathrm{mm}$ intervals in each specimen. Design flexural strength was $18.7 \mathrm{kN}$ and design shear strength was $7.6 \mathrm{kN}$. So the specimens were designed the cross-section could lead to the condition that flexural failure was dominant.
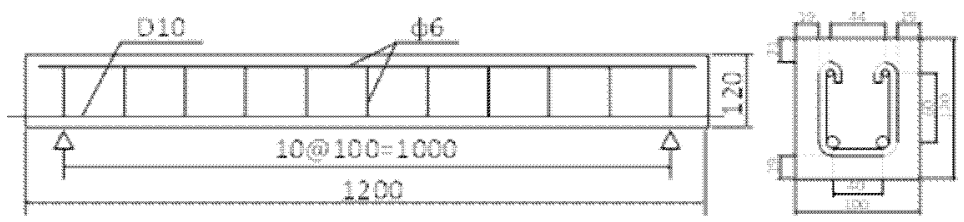

Figure 1. Arrangement of reinforcement and dimensions of the specimen (unit in $\mathrm{mm}$ ).

In this study, the electrolytic corrosion method was adopted to make the damaged RC beams with corroded reinforcement. This electrolytic corrosion method is one of the methods to accelerate corrosion of reinforcement [3]. In this test, DC power supply was used. In addition, a copper sheet was used as a cathode. The cathode and the specimen were placed in $3 \% \mathrm{NaCl}$ solution as shown in Figure 2. The corrosion rate of the reinforcements was controlled by energization time.

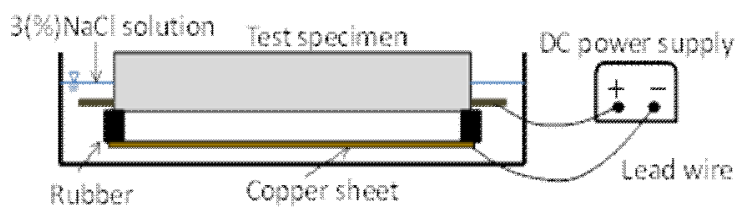

Figure 2. Schematic view of electrolytic corrosion method.

After the loading test, reinforcements were taken out from the specimen and the corrosion rate of the reinforcements was measured. Now, the corrosion rate is calculated according to the following Equation (1).

$$
C=\frac{w_{0}-w_{c}}{w_{0}} \times 100
$$

where $C$ is corrosion rate, $w_{o}$ is the mass of no corroded reinforcement, and $w_{c}$ is the mass of corroded reinforcement. 
As a result, Table 1 shows measured corrosion rate as any specimens. Further, in specimen's name, $\mathrm{D}$ expresses an impact test, $\mathrm{S}$ expresses a static loading test and $\mathrm{N}$ expresses a no damage specimen, $\mathrm{L}$ series expresses a degradation level of specimen. Moreover the crack situations of the specimens after the electrolytic corrosion test were shown in Figure 3. By the expansion of volume due to the generation of corrosion products, cracks in the axial direction of the tensile reinforcements could be confirmed. The corrosion conditions of the tensile reinforcements after derusting are shown in Figure 4. When the corrosion rate increases, a clear bias occurred in the corrosion distribution of tensile reinforcements.

Table 1. Corrosion rate for any specimens.

\begin{tabular}{|c|c|c|}
\hline For any tests & Name of Test Specimen & Corrosion Rate (meV) \\
\hline \multirow{4}{*}{ For Static Loading Test } & S-N & 0 \\
\cline { 2 - 3 } & S-L1 & 0.67 \\
\cline { 2 - 3 } & S-L2 & 0.94 \\
\cline { 2 - 3 } & S-L3 & 6.13 \\
\cline { 2 - 3 } For Repeated Impact Test & S-L4 & 11.71 \\
\cline { 2 - 3 } & D-N & 0 \\
\cline { 2 - 3 } & D-L3 & 7.03 \\
\hline \multirow{3}{*}{} & D-L4 & 11.04 \\
\hline
\end{tabular}

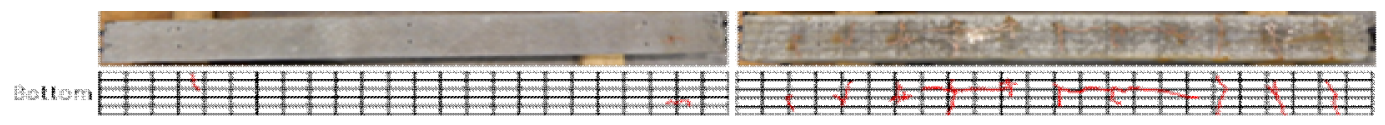

(a) S-L1

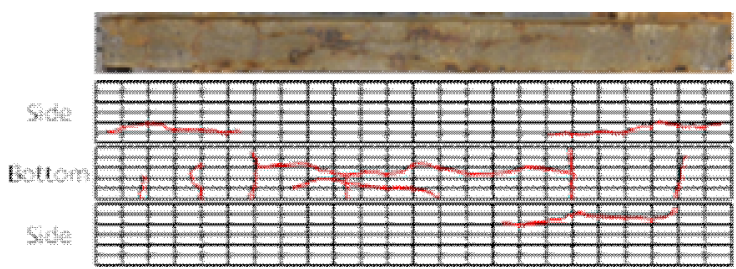

(c) S-L3 (b) S-L

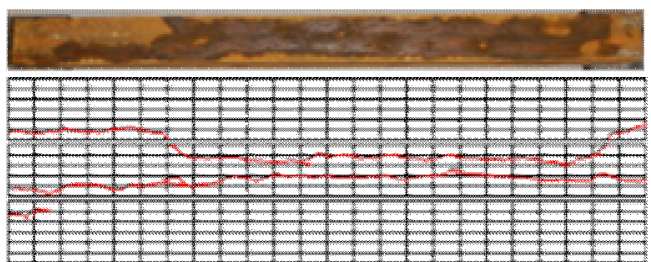

(d) S-L4

Figure 3. Crack situations due to corrosion.

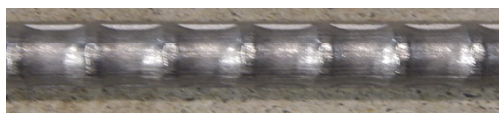

(a) S-L1

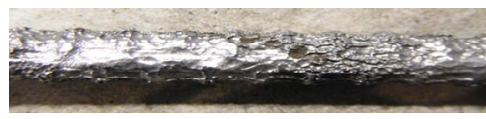

(c) S-L3

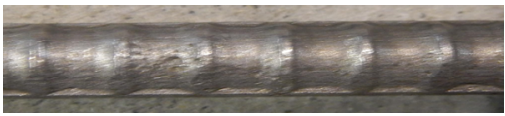

(b) S-L2

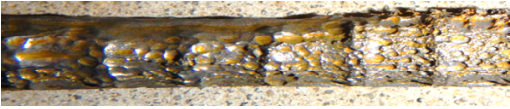

(d) S-L4

Figure 4. Corrosion condition of the tensile reinforcements after derusting. 


\section{Static Load Capacity}

\subsection{Experimental procedure}

The static loading test was conducted in order to clarify the static flexural load capacity of the RC beams with corroded reinforcement. A universal testing machine was used for acting compressive loading on the beams. As the loading condition, 2 points concentrated load of equal bending moment section $200(\mathrm{~mm})$ was adopted as shown in Figure 5, and as the loading rate, about $0.5(\mathrm{~mm} / \mathrm{min})$ was controlled because of avoiding the effect of the loading rate. In this test, the acting load and displacement at the mid-span of the RC beams were measured as the measurement item.

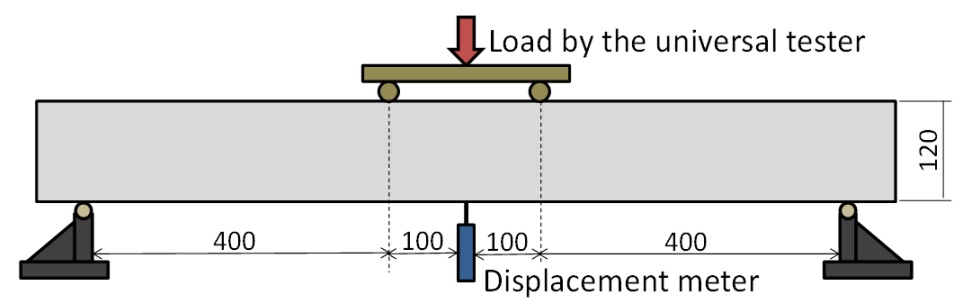

Figure 5. Schematic view of the static loading test (unit in $\mathrm{mm}$ ).

\subsection{Results and discussion}

At first, the load-displacement relations are shown in Figure 6 as one of the results of the static loading test. Regarding the process to the fracture in case of S-N (Uncorroded), the flexural cracking occurred at $5 \mathrm{kN}$, after that the reinforcement steel yielded at $23 \mathrm{kN}$ and then the beam fractured due to bending at $26 \mathrm{kN}$. Like this, when the displacement at the mid-span of the beams reached 3 4 (mm) in all cases, stiffness fell with a reinforcement yielding, and after the load reached the maximum, the load was indicated the behaviour which was fallen gradually.

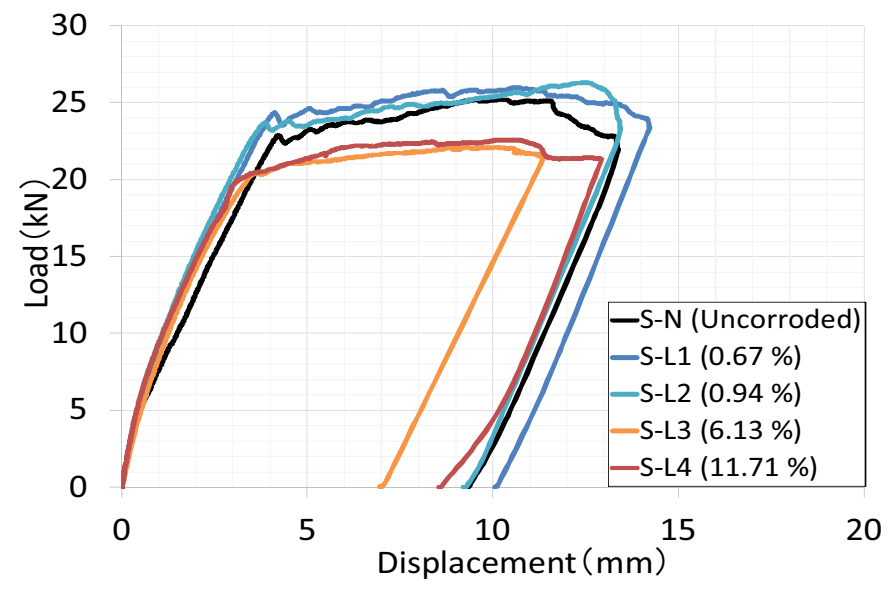

Figure 6. The load-displacement relations.

However, the stiffness degradation due to the occurrence of flexural cracking was not able to be indicated in case of S-L1 L4 (Damaged RC beams). This result could be due to the existence of initial cracks occurred with corrosion. In addition, Table 2 shows the relationship between maximum load and corrosion ratio in all cases. From this table, the maximum load became lower in case of S-L3 
(corrosion rate: 6.13\%) and S-L4 (corrosion rate: 11.71\%) compared to S-N (Uncorroded) as expected, while the maximum load became slightly larger in case of S-L1 (corrosion rate 0.67\%) and S-L2 (corrosion rate $0.94 \%$ ). As these reasons, the influence of the increase of density between rebar and the surrounding concrete by expanded reinforcements due to corrosion becomes more dominant than the influence of the cross-sectional area reduction due to rusting reinforcements in the area with the small corrosion rate. And influence of decrease of a cross-sectional area and a decline of adhesion by corrosion of a reinforcement become dominant in the area with the high corrosion rate.

Table 2. The relationship between maximum load and corrosion ratio in all cases.

\begin{tabular}{|c|c|c|c|}
\hline Name of Test Specimen & Maximum Load (kN) & Maximum Load Ratio & Corrosion Rate (\%) \\
\hline S-N & 25.72 & 1 & 0 \\
\hline S-L1 & 25.98 & 1.01 & 0.67 \\
\hline S-L2 & 26.32 & 1.02 & 0.94 \\
\hline S-L3 & 22.11 & 0.86 & 6.13 \\
\hline S-L4 & 22.6 & 0.88 & 11.71 \\
\hline
\end{tabular}

\section{Impact Load Resistant Capacity}

\subsection{Experimental procedure}

The impact loading test was conducted in order to clarify the impact load resistant capacity of the RC beams with corroded reinforcement. In this test, a falling weight type impact test indicated in Figure 7 was adopted. No damage specimen (D-N) and reinforcement corrosion specimens (D-L3, corrosion rate: $7.03 \%$ and D-L4, corrosion rate: $11.04 \%$ ) were used. As the loading condition, a 100kg steel weight was dropped freely onto the top surface of the RC beams at mid-span at repeatedly until the fracture of the beams [4]. Here, in this test, fracture of the beams was defined the time when accumulation residual displacement reached $1 \%$ of the span length. The impact velocity was set at $1.0 \mathrm{~m} / \mathrm{s}$ in order to make the maximum displacement does not exceed the reinforcement yield displacement that was confirmed in static conditions by tests conducted beforehand. The impact load by a load cell and the residual displacement at the mid-span of the RC beams were measured as the measurement item.

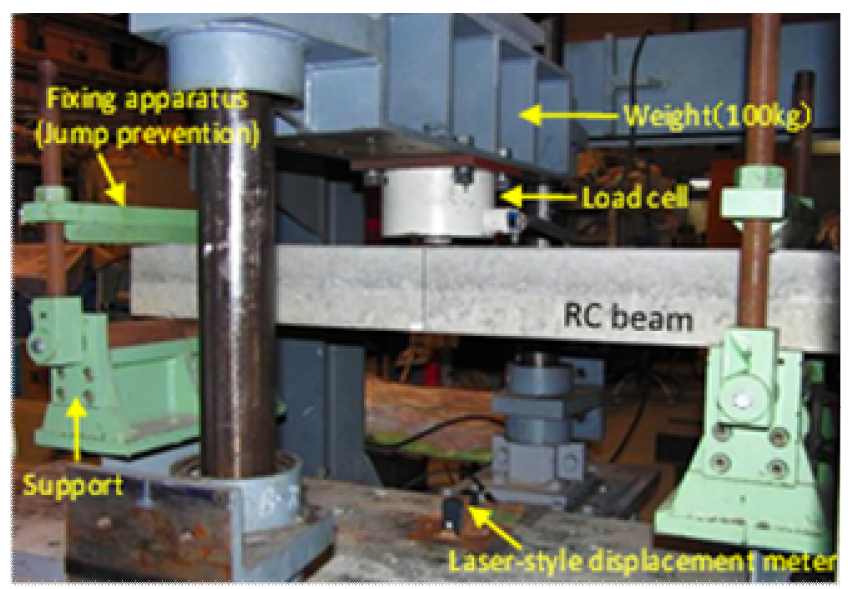

Figure 7. Experimental apparatus (falling weight type impact test machine). 


\subsection{Results and discussion}

First, from the impact force and displacement response of the first impact as shown in Figures 8 and 9, as the level of degradation was increased, impact force response was smaller and displacement response was larger. It could be that resistance against impact force of specimens has declined by corrosion of reinforcements. From the relationship between the accumulation residual displacement and the number of impacts shown in Figure 10, number of impacts to the failure was 75 times in the D-N, 32 times in the D-L3, 16 times in the D-L4 and it was able to confirm that the impact resistance was greatly reduced by corrosion of reinforcements. In addition, the fracture patterns are shown in Figure 11. In D-N, first, flexural cracks were occurred just below of the impact point. Then, with increasing number of impacts, the width of the crack became larger and cracks spread to the entire specimen. On the other hand, in the D-L3 and D-L4, flexural cracks were occurred just below of the impact point and the cracks which had caused by corrosion became larger with increasing number of impacts at the same time.

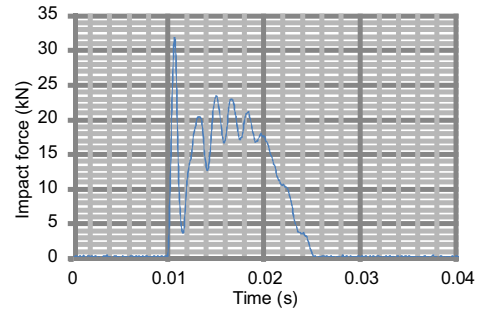

(a) $\mathrm{D}-\mathrm{N}$

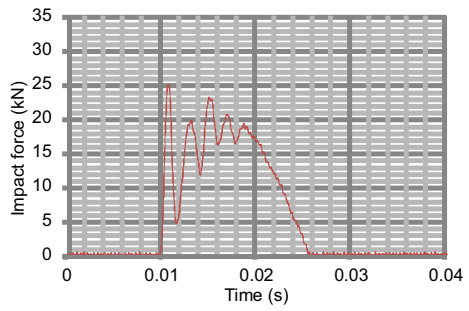

(b) D-L3

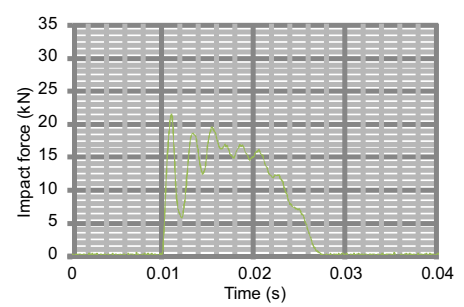

(c) D-L4

Figure 8. Impact force response at the first impact.

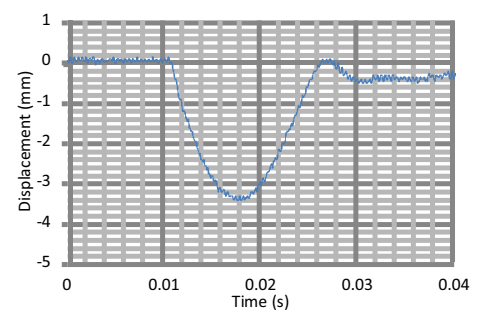

(a) D-N

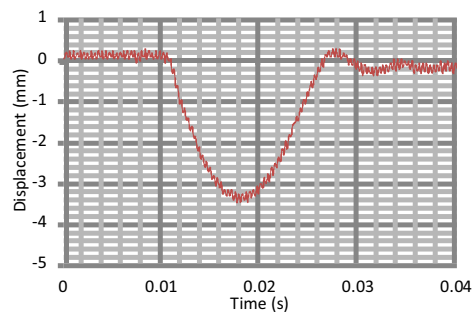

(b) D-L3

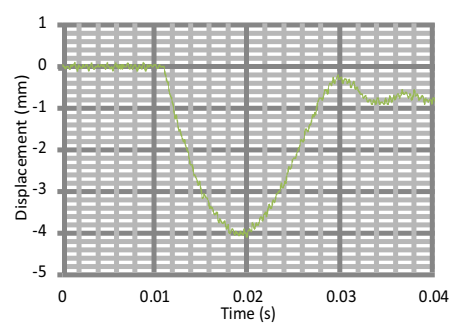

(c) D-L4

Figure 9. Displacement response of the beam at mid-span at the first impact.

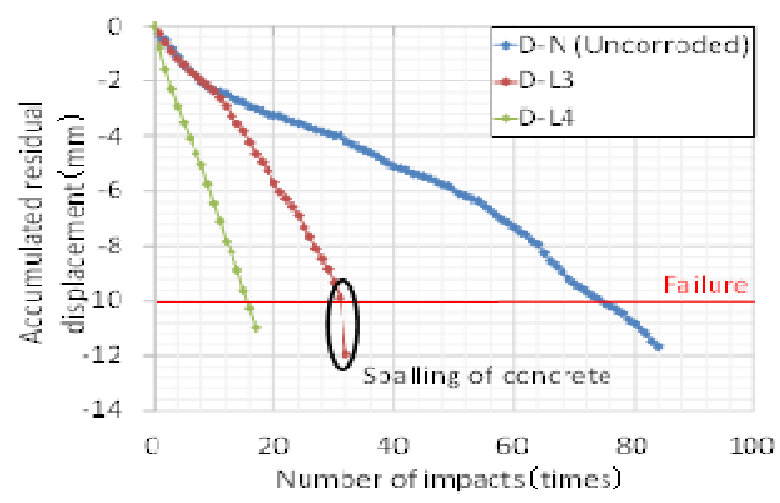

Figure 10. The relationship between the accumulated residual displacement and the number of impacts. 


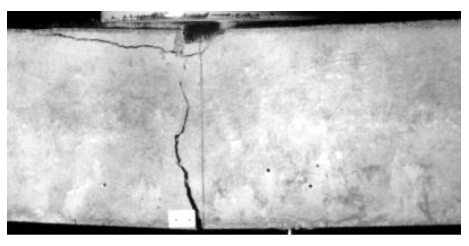

(a) D-N

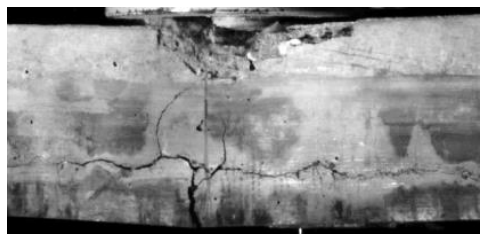

(b) D-L3

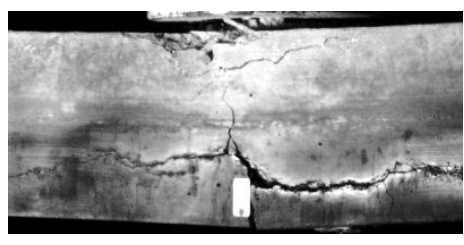

(c) D-L4

Figure 11. Fracture pattern.

\section{Conclusion}

The objective of this study is to get fundamental findings regarding impact load capacity of damaged $\mathrm{RC}$ beams with corroded reinforcement through the impact loading test. The followings are confirmed from this study:

i. The impact resistance capacity of the damaged RC beams also decreased with the increasing corrosion ratio through repeated impact test results. It is also found that the existence and pattern of cracks due to corrosion had an obvious effect on the impact resistance capacity based on the number of impacts to fracture.

ii. Even though the corrosion rate is same level, the Impact load resistant capacity reduce greatly compared to the static load resistant capacity because of the existence and pattern of cracks due to corrosion.

\section{References}

[1] H. Zhou, J. Lu, B. Dong and F. Xing, Effects of stirrup corrosion on bond-slip performance of reinforcing steel in concrete, Constr. Build. Mater., 93, 257-256, (2015).

[2] L. Yu, R. Francois, V.H. Dang, V. L'Hostis and R. Gagne, Structural performance of RC beams damaged by natural corrosion under sustained loading in a chloride environment, Eng. Struc., 96, 30-40, (2015).

[3] O. Michiaki, K. Toshiyuki, Y. Yasuhiko and S. Tsutomu, Influence of corrosion of reinforcing bars on bending performance of reinforced concrete members, J. of Materials, Concrete Structures and Pavements, 62(39), 542-554, (2006).

[4] I. Mitsuya, S. Yuji and Y. Hiroshi, Structural behavior of reinforced concrete beams subjected to repeated impact loads, Technical Note of the Port and Airport Research Institute No.1152, Japan, (2007). 